\title{
Editorial
}

\section{A call to luxury}

Journal of Revenue and Pricing Management (2016) 15, 85-86. doi:10.1057/rpm.2016.25

According to research by the Future Foundation (2014), millions of consumers now feel entitled to luxury in some form and while it is certain that the prolonged global financial crisis has subdued the growth of prosperity in many developed countries, our sense of entitlement to luxury is irrepressible. In countries where GDP per capita is comparatively lower, the feeling that luxury goods and experiences are there to be had for immediate enjoyment will not be nearly as entrenched - their power here has so far been aspirational as much as anything else. But the distribution of effective demand is changing this picture. As access to luxury becomes more mainstream, its very definition evolves to carry ever more nuanced associations alongside more traditional ones. While the meaning of luxury for consumers with newfound wealth is likely to be more rigidly wedded to its classic, traditional definition of expensive, unique material quality, we note too that intensity of experience is becoming more important to global consumers - indeed any form of indulgence that enables them to fulfil deeper psychic ambitions - and confirm one's social success and savoir-vivre in the process. Underpinning the Luxury Experienced trend is the notion that the leisure activities and moments one engages should contribute to skill set, cultural awareness or even character - that superior experiences have a lasting impact on one's personal outlook and therefore represent an investment. And that ultimately such endeavours (and improvements) can be broadcast across networks, both on- and offline.

From a business perspective, Spa L'Occitane (spa.loccitane.com/) introduced Spa La Vie, an 8000 square foot Mediterranean Wellness Sanctuary situated in Mumbai. Spa La Vie follows the global roll-out of a number of L'Occitane spas since 2001. Spa La Vie offers several L'Occitane therapies, including soaking ceremonies and scrubs and is presented as 'an Ayurvedic experience' in a 'luxurious traditional setting'. The MGM Grand Hotel (www. mgmgrand.com ) in Las Vegas has been offering a number of what it calls Stay Well Rooms. For an extra US $\$ 30$ per night, travellers can make use of 'wellness' technology developed by the hotel in collaboration with Delos, the Cleveland Clinic and Dr Deepak Chopra. The additional amenities include advanced light technologies that help regulate melatonin production and ease jetlag, a simulator alarm that gradually wakes up the body, air purification facilities and a Vitamin C infused shower.

Where access to luxury goods has become more widespread, the very notion of luxury attracts more subtle associations and its meaning becomes more fluid. Often luxury will be less of an object or a possession and more of an experience (a concierge-type service, a Michelin meal in an exclusive locale, a club membership, a relaxing retreat with knowledge-enhancing day classes ...). The desire for new and enriching experiences extends into more and more consumption areas, but continues to have special energy in the out-of-home leisure, retail and travel sectors. It is those brands that can deliver experiential value beyond basic function that will be particularly competitive here. For the retail sector, innovations that look to premiumise aspects of the retail experience, through both concierge services and experiential stores, 
speak directly to the trend. More, we note the growing prevalence of services that offer to curate experiences on behalf of the consumer based on preferences, safeguarding a sense of novelty and exclusivity at minimal effort. Experiences that can speak directly to desire for skill acquisition, that have a sense of purpose, that are associated with the greatest experiential-aspirational value ... these will be the activities sought by experience-hungry consumers. As materially driven displays of personal success are seen as distasteful by many (but not all), invitations to broadcast success in more inconspicuous ways will likely hold appeal.

\section{PREMIUM AIR TRAVEL}

According to the latest data from IATA (2015) in December 2015, premium traffic volumes grew by an estimated 3.7 per cent in 2015 as a whole. This growth was adhered to strong economic performance in advanced economies on the North Atlantic. Even with economic slowdown in China and Brazil the premium market is holding up. However, premium-class traffic growth lagged behind that of its economy counterpart on most origin-destination markets towards the end of 2015. This is of course not surprising given that economy travel is more price sensitive than business-related traffic, and economy traffic has responded as lower fuel prices translated into lower airfares during 2015.

Premium traffic on the North Atlantic - the largest market in terms of revenue - is estimated to have grown by a healthy 4.5 per cent in 2015 as a whole, supported by solid economic growth in the United States and a modest cyclical upturn in Europe too. By contrast, the weakness of premium-demand drivers in emerging Asia means that premium volume growth underperformed significantly on some of the region's key passenger markets. The underperformance of premium travel was most stark on the origin destination within Asia market and also to and from Europe. The one exception was on the Trans-Pacific, where exposure to the stronger US economy looks to have helped to support demand and premium volumes. This was particularly the case on the Trans-Pacific and Europe-Asia markets, which together account for just over one-quarter of industrywide premium-class revenues. In the current environment where lower fuel prices and competition in the industry are placing downwards pressure on economy yields, the high-yielding premium-segment offers an important buffer for overall airline financial performance.

\section{A CALL TO RESEARCH}

In 2017, a special issue of the Journal of Revenue $\&$ Pricing Management will publish a series of papers on premium pricing and luxury. What are the concepts and attributes linking premium pricing and luxury? Is it quality, perceived fairness, exclusivity or extended self? How do airlines and hotels model price sensitivity? What is the link between price and product? Would you overbook a first class passenger? The purpose of the special issue is multidisciplinary, from management science models to a social sciences perspective. All exploring luxury and premium pricing. If you are interested, please submit an abstract to ian.yeoman@vuw.ac.nz by 31 May 2016. Full details available at www .palgrave-journals.com/rpm/index.html

\section{REFERENCES}

Future Foundation (2014) Luxury experienced, https://nvision. futurefoundation.net/, accessed 14 February 2015.

IATA (2015) Premium market, http://ht.ly/YEJO3, accessed 24 February 2016. 